\section{Endotracheale Intubation - Risiken und ihre Minimierung}

Die neonatologische Intensivmedizin gehört zum höchsten Risikobereich in der hospitalen Patientenversorgung. In einer aktuellen Ausgabe des Journal of Pediatrics wurden unerwünschte Ereignisse im Rahmen von endotrachealen Intubationen Neugeborener analysiert. n einer prospektiven Beobachtungsstudie am Vanderbilt University Medical Center in Nashville, Tennessee, einer 100-Betten-Neonatologie, wurden über einen Zeitraum von 10 Monaten 273 orale Intubationen auf Station an 162 Patienten ausgewertet. Unerwünschte Ereignisse wurden in minderschwere (z.B. ösophageale Fehlintubation, die rasch erkannt wurde, oder lokale Blutung) und schwere (z. B. therapiebedürftige arterielle Hypotonie oder Pneumothorax; Abb. 1) unterschieden. Unerwünschte Ereignisse traten bei $39 \%$ der Neugeborenen auf, davon schwere in $8,8 \%$ der Fälle. Die Quoten verdoppelten sich mit jedem weiteren Intubationsversuch und vervierfachten sich bei einer Notfallintubation, die wiederum bei $62 \%$ Folge einer ungeplanten Extubation war.

Hatch LD et al. Endotracheal intubation in neonates: a prospective study of adverse safety events in 162 infants. J Pediatr 2016;168:62-66

\section{Kommentar}

Es liegt in der Natur einer Beobachtungsstudie, dass sie nur Assoziationen aufzeigen und keine Kausalitäten belegen kann. Es ist

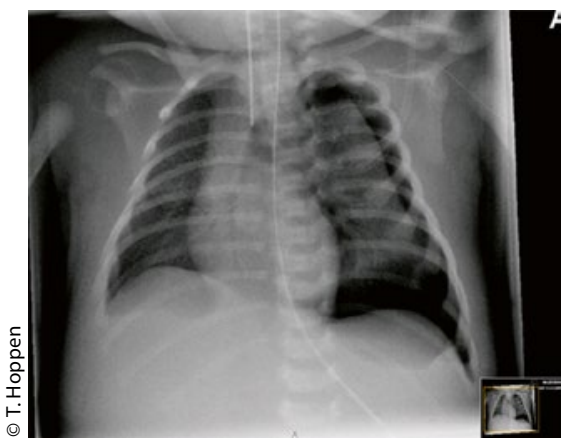

Abb. 1: Seltene, aber gefürchtete Komplikation: Pneumothorax links nach endotrachealer Intubation jedoch sehr plausibel, dass der Intubationserfolg wesentlich von der Erfahrung des Durchführenden abhängig ist. Über Maßnahmen zur Reduktion einer hohen „Spon- tanextubationsrate" wurde bereits früher in dieser Rubrik berichtet [pädiatrie hautnah 2015;27:12-3; Quelle: Merkel L et al. Pediatrics 2014;133:e1367-72]. Sehr hilfreich ist auch die Verwendung von Checklisten, insbesondere zur frühzeitigen Einteilung von Patienten mit einem absehbar schwierigen Atemweg. Das ganze Team muss wissen, was im Einzelfall prospektiv gerichtet sein muss. Abb. 2 zeigt einen auf die Verhältnisse unserer interdisziplinären neonatologisch-pädiatrischen Station abgestimmten „Intubationsstandard“.

Dr. Thomas Hoppen

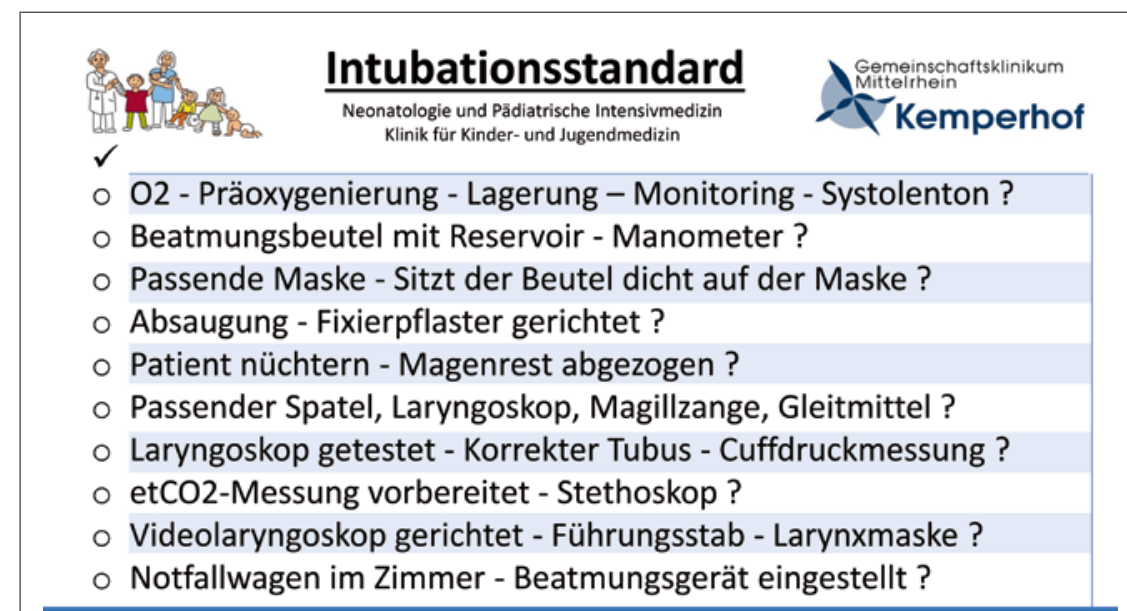

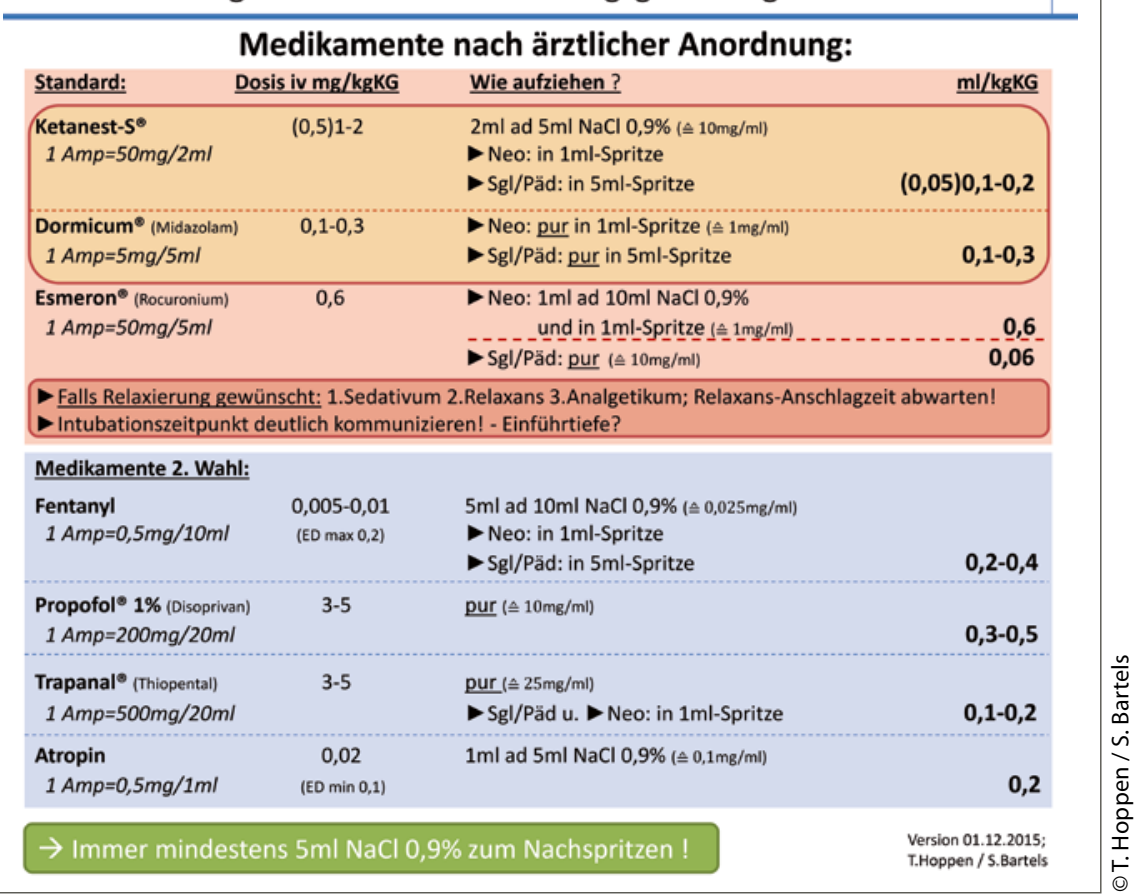

Abb. 2: „Intubationsstandard“ der Klinik für Kinder- und Jugendmedizin, GK Mittelrhein, Kemperhof Koblenz. Aufgrund der gefürchteten Nebenwirkung einer Kreislaufhypotonie durch Midazolam kommt bei Frühgeborenen $<32$ SSW möglichst nur noch Ketanest zum Einsatz. 